\title{
Erratum zu: Unternehmenskulturentwicklung im Projekt WIND - Vorgehensweisen, Instrumente und Methoden
}

\section{Erratum zu:}

Kapitel 2 in: M. Zirlik (Hrsg.), Unternehmenskultur entwickeln in der Sozialwirtschaft, https://doi.org/10.1007/978-3-658-28563-0

Das Kapitel wurde mit einem falschen Autorenname publiziert. Dies wurde korrigiert und der korrekte Name ist Yvonne Mattes.

Die korrigierte Online-Version dieses Buches finden Sie unter https://doi.org/10.1007/978-3-658-28563-0

https://doi.org/10.1007/978-3-658-28563-0_2 